interesting as a factor in the production of the otitis, for no other cause could be set down in the history of the case.

This contribution may be justified by the rarity of such cases in otological literature. The latest specimen, and one of the most interesting and important, consisting as it does of a sequestrum of the whole labyrinth, has been described by the President of this section in the pages of the Glasgow Medical Journal for April if las year. Two years hefore (Jounxal, June 13th, 1885) that contribution was made we were indebted to Mr. Pye, of London, for elaborate notes of a case of the same kind. Mr. Phillips, of the Bolton Infirmary, had also a similar case about the same date. These form the most recent memoirs on the subject in the annals of otology in England. But members will have observed with great interest the most elaborate paper on necrosis of the labyrinth by Bezold, of Munich, that appeared in the Archives of Otology for December of last year, in the course of which a comparatively complete list is given of all the reported cases accessible to him, including five of his own. These amount to forty-six, of which he gives a very critical analysis. In addition to these forty-six there are about eight others of which he had not heard or had not obtained particulars while preparing his paper. One of these was reported by Hartmann, of Berlin, in the previous number of the Archives, the sequestrum described by sim consisting of a portion of the cochlea, including about the two upper turns. Seeing that the records of aural surgery in this country and the Continent only contain notes of over fifty cases of the separation of sequestra of the labyrinth in whole or in part, perhaps the members of this Section will not grudge me the few minutes I have occupied in reading my notes of a recent additional case.

Notes regarding an unusually large Auricular Appendage.H. Q., aged 29, weaver, came to the Glasgow Ear Institution, last September, for the purpose of inquiring whether a very unsightly itppendage, projecting in front of her right ear, could be removed without danger. Apparently, matrimonial prospects had suggested the inquiry with a view to improving her appearance. In the position of the tragus, there were found a very minute nodule and the appendage now shown, in front of it-and on a slightly higher plane. The large projection was directed forwards and upwards. Its base measured half an inch, and its length from base to apex was over an inch. The crest of the helix approximated very closely to its upper border, and it extended downwards to the incisura intertragica. A small nodule could be felt ust below the crista helicis. Another was present at the lower border of the base of the large appendage. The hearing was perfect.

Under chloroform, the whole of the large projecting structure was removed from its very base by one snip of large scissors. The stump of cartilage which appeared slightly above the level of the skin was pared away as deeply as possible, and the edges of the wound brought together by a wire suture. It was dressed with dry boric lint, and healed perfectly by first intention.

Small nodules, projecting from various parts of the auricle, are common enough, and Virchow has described such auricular appendages; but I had never seen one so large as the one shown. That is my reason for bringing it before the notice of the Section.

Such specimens as these form examples of the collection of curiosities which every man makes who has the opportunity of examining a very large number of cases in one special department of disease, and no doubt members have many remarkable specimens in their possession. Practising as the most of us are in large towns, we have not the opportunity of exhibiting them except at meetings of societies of general practitioners, where their importance is not sufficiently appreciated. It is exceedingly rare that we can have such an opportunity as the present occasion. It seems to me, therefore, that the President's suggestion of a combination of otologists is most worthy of practical adoption. There might be a Society in Scotland, consisting of the aurists in Edinburgh and Glasgow, which could meet a number of times a year in either of those cities. Similar associations might be formed in England and Ireland. Such meetings would do very much to facilitate the inter-communication of experience and information on the part of individuals, which could not fail to benefit the whole of those surgeons working in this department of disease.

THE Camberwell Guardians have increased the salary of Dr. Samuel Hague, medical officer for the St. George's district, from $£ 130$ to $£ 150$ per annum.

\section{ON THE TRUE VALUE OF THOSE AIDS TO HEARING USUALLY TERMED ARTIFICIAL TYMPANIC MEMBRANES.}

Read in the Section of Otology at the Annual Meeting of the British Medical Association, held in Glasgow, August, 1888.

BY W. LAIDLAW PURVES, M.D. Aural Surgeon, Guy's Hospital.

In considering the true value of the artificial drumbead, it should be remembered that the ear, the organ of tune, is suited to receive transverse sonorous vibrations, and that what is required of the ear is: 1. An appreciation of noises. 2. The determination of direction. 3. The determination of intensity. 4. The recognition of a combination of impulses.

We need not, at present, regard the artificial membrane in relation to the two requirements first mentioned. The last two requirements are those which come practically before the surgeon, and they included the others to a great extent. Our assistance is not asked by a patient to enable him to hear the tick of a watch, or the sound of a fork, but to restore him, as far as may be, to conversational intercourse with his fellow men.

This conversational intercourse is interfered with by any changes which damage the mechanism regulating the intensity, the analysis of the several impressions, the conveyance of these to the brain, or the sensations thereby produced. It is with the first cause-changes in the mechanism regulating the intensitythat we have to deal. These are found in abnormal alterations in the reflection, resonance, conduction, and tension of the external and middle ears, and almost exclusively on those in the latter organ.

The changes in the meatus itself, excluding those in the membrana tympani, in which the artificial drumhead might be of service, are somewhat obscure, but cases have come before me in which the benefit effected seemed to be in the size and position of a piece of moistened cotton wadding in the meatus. I shall be happy to learn if any such cases have been seen by any member present, as I have not observed such cases mentioned in the literature of the subject. The so-called, but in such cases mis-called, artificial drumhead is made in the form of a cylinder, and placed on the floor of the meatus, but so that no part of it reaches the natural membrane, or its position in the normal state. If we remember that the vibrations collected by the auricle, and those which strike the meatal wall perpendicularly are reflected frequently in the meatus; and these reflections are influenced by changes in the regularity of surface, both in the cartilaginous and osseous portions of that canal; that these reflected vibrations then strike a membrane standing at an angle of about $140^{\circ}$ to the canal causing those reflections; and that this canal acts as a resonator to certain tones, strengthening high tones, and deadening low ones, we must admit that the placing of a body which changes the calibre of the canal irregularly may alter its capacity for exercising these functions, and, when abnurmal changes are present, may assist in restoring that capacity.

It may be that in cases of abnormal change in the membrana tympani itself, wichout meatal changes, this meatal pad may reflect or concentrate vibrations to a part of the tympanum better fitted to receive and convey them to the inner ear.

When we turn to the tympanic membrane itself, and the cavity of which it forms the outer wall, and note its irregularity in stiffness, its irregularity in density, in tension, in movement, and in curvature, the changes which may occur by the placing of an artificial drumhead against a tympanic one in which abnormalities are present are innumerable. When we pass to the cavity with its muscles, joints, ligaments, linings, membranes, and peculiar nervous supply, and then remember that any changes which may arise either in the membrana tympani or in the cavity, must cause anomalies in their relations to each other, is it a matter of astonishment that there has been difficulty in determining the exact mode of action of the artificial drumhead?

It may be that it acts in the many ways alleged, as by restoring the screen between the meatus and cavity, and so increasing the resonant power of the latter, by acting as a medium between 
the air and the ossicles, or by restoring a lost curvature and so increasing the action of the vibrations on the ossicles. It may load the membrane so as to prevent after-vibrations, or enable the membrane to accommodate itself to vibrations of every degree of rapidity. It may and does act as a protector, as a vehicle for medicaments, as an absorbent, as a moistener; but it is pre-eminently as a tension transposer, and an assistant to the intratympanic muscles that it effects the changes which delight both patient and practitioner.

When accommodative loss has taken place in the ear from anomalies of tension, as (1) by a lengthened closure of the Eustachian tube, causing rarefaction of the tympanic air, and thereby an increased tension of the membrana tympani and ossicula, and so causing a hindrance to the conduction of sound; $(2)$ by thinning of the membrane by atrophy or cicatrices, or thickening of the same by deposits, and so causing a disturbance between the tension of the membrane and chain; (3) by ossicular changes, especially at the joints or articulating surfaces, interfering with easy conduction-then the artificial drumhead may be applied with a prospect of success.

We are, however, unable to say before trial in what position our assistant is to be employed, and this is only determinable by trial. We may conjecture by observing the changes present in the drumhead by means of a magnifying lens, and the variations in the tension thereof by means of a Siegel's speculum, whether an increase in the tension or a relaxation of the ossicles is most likely to benefit; but I know of no method by which you can predict an improvement to conversational hearing before trial.

Should the loss of accommodation have arisen from a general cause, such as anæmia, nervous prostration, or other general impairment of vitality, we cannot look for improvement by a local application of this kind; but we are able to differentiate the loss in the two different classes of cases, by the presence in the class in which the artificial drumhead is of benefit, of the objective symptoms above mentioned, and in the other by the general condition or the presence of paretic conditions in the eye, pharynx, or larynx. There may be a combination of causes present, each requiring the attention of the surgeon.

We have still to deplore the want of a good standard for accurately determining the degree of loss for conversational hearing, which is the province in which the artificial drumhead achieves its greatest victories-victories which, in suitable cases, are unsurpassed in any domain in surgery. I have heard it averred in public discussion by a well-known surgeon in London that the membrana tympani acted as a protection or covering to the cavity, and nothing more. I have read the report of a scientific meeting in which it was stated that the artificial drumhead was "a pretty scientific toy, and occasionally very satisfactory in its effects." As well may we consider the transparent refracting media of the eye merely coverings and protectors of the retina, and the spectacle lens " a pretty scientific toy!" How such enunciations could be calmly delivered by men practising aural surgery, and who must surely have seen the delight of the patient to whose ear an artificial membrane has been successfully applied, the eager inquiries for instruction in its use, and the satisfaction evinced after many months of easy hearing, free from that constant strain to listen which was causing nervous prostration, headache, and giddiness by the very effort, I cannot understand. I have heard the successful application of the artificial drumhead compared to the successful operation for cataract, but I would rather say that the artificial membrane does for the ear what the artificial lens does for the eye, performing the work which the muscles themselves cannot do without a strain, and placing the vibrations and undulations in the respective organs within the easy command of the muscles, so that those wonderfully minute variations necessary for conversational hearing may be effected with comfort-variations which are constantly being acted upon in our waking hours by the guardians of the gates of the two great senses.

\section{SECTION OF PSYCHOLOGY.}

Wednesday, ThURSdat, AND FridaY, AUGUST 8TH,9TH, AND 10TH. Remarks on Boarding Out as a Provision for Pauper Insane.Dr. TuRnBulL described first the object of boarding out as an effort to do for pauper patients what was done, and rightly done, by the relatives in the case of many non-pauper cases. Its aim was to provide domestic care for a certain class of the pauper insane, by selecting suitable guardians and placing the patients in homes in suitable districts. It was only done in cases in which asylum treatment could not do anything further to promote recovery, and asylum control was not necessary for restraining any dangerous or offensive habits. Financially the boarding out system was much cheaper than the cost of care in asylums, or in lunatic wards of poorhouses: and if efficiency was not sacrificed, economy was a strong argument in its favour. The advantages were (1) that it provided a natural, healthy, and satisfactory mode of accommodation for a certain class of the insane; (2) it was economical; (3) it lessened the pressure on the accommodation of asylums, and allowed these latter to turn more to their proper purpose of acting as hospitals for the cure of the insane. The requirements were, (1) a selection of suitable patients, $(2)$ a selection of suitable guardians, and (3) efficient inspection by a central authority. The class of patients suitable for boarding out were those suffering from either congenital or acquired insanity, who were in the quiet manageable stage, generally incurable, but not necessarily so. The contra-indications to boarding-out were (1) presence of dangerous propensities, (2) habits making the patient offensive to public decency, and (3) the risk of sexual accident. Regarding the number of patients suitable for boarding out, Dr. Turnbull said that in Fife it represented a proportion of 16 per cent. of those who came under asylum treatment. Taking all the cases which came on the registers of the parish as insane, whether they had needed asylum treatment or not, the experience of the city parish of Edinburgh showed that 28 per cent. could be provided for by boarding out.-Dr. YELLOwLEES desired to thank Dr. Turnbull for an admirable and temperate defence of the boardingout system. He said that no one would question the value of boarding out pauper patients, given suitable cases, suitable guardians and proper supervision; but that such combination was very difficult to obtain, and in some districts, where high wages were earned, simply impossible. The patients were not received by guardians from pure benevolence, but they expected to profit by their boarders, and only in a poor home could the profit made out of $6 \mathrm{~s}$. or $7 \mathrm{~s}$. a week be an object if the patient were not neglected. Even at the best, Dr. Turnbull's paper showed that only 16 per cent. of our asylum population could thus be provided for, and such an outlet was utteriy inadequate as a provision for the constant accumulation of chronic insane in our asylum wards. Of course it was a very welcome relief so far as it went, but something more was needful. He believed that the insane of any area should be received into small cure asylums-as numerous as the area might require - from which the patients whose recovery had become doubtful should be transferred to a large chronic asylum, or restored to friends, or boarded out with strangers, as might be found best. Dr. Yellowlees gave some details as to the mode of providing for such patients in the United States as seen at the asylums at Willard and at Middletown. With the one drawback of being too costly, such provision was admirable, and boarding out was there found to be impossible.-Dr. HACK Tuke said that what struck him forcibly was that, after eliminating the unsuitable cases out of the chronic insane, a comparatively small number remained to be provided for. $\mathrm{He}$ thought that while we looked to the interests of patients and the ratepayers we were too apt to overlook the moral injury which might be done to the family, especially the younger members, with whom the patient was placed. It appeared that the Scotch Lunacy Board regretted the number now aggregated together at Kennoway, etc. If so, the difficulty of meeting the evils of the great accumulation of chronic cases in asylums was evident, and the advantages to be derived from boarding out proportionately limited. At the same time, he fully recognised the value of the cautious use of boarding out, so long as careful and frequent inspection was in force. In England there were 6,000 pauper lunatics and idiots boarded out and placed under the official inspection of local parish medical men, but without the supervision of the Lunacy Board. In this respect there was a marked difference between the Scotch and English systems of boarding out. He (Dr. Tuke) had visited Gheel, and no doubt there was much that was unsatisfactory as well as satisfactory in that system, but it would not be fair to compare it to that in force in Scotland, unless the latter went on increasing until there was one-third of the population of the colony insane. It was clear that many abuses might arise in the one case and not in the other. On the other hand, it should in fairness be remembered that there was a good asylum in the midst of the Gheel colony, so that cases proving unsuitable for the village life could at once be removed to the asylum. He thought a strong argument in favour of the 
boardingout system was its greater cheapness, for so long as no mischief was done to families, it was a duty to lessen the present enormous expense of our county and borough asylums by a recourse to more economic methods of caring for the chronic insane.-Dr. STEARNs said that when in this country, several years since, it was his good fortune to visit one of the colonies of the boarded-out insane, where he had the fullest opportunity to observe its operation. He saw no reason to think that the plan was not a successful one in Scotland, and on his return to the United States he had occasion to consider its desirability there. He was forced, however, to the conclusion that, aside from any other objections to the plan there, there existed this insurpassable one, namely, the impossibility of securing reliable and proper persons to take charge of them, except at such expense as would render such provision impracticable. In the United States the rate of wages was so high that reliable persons and those possessed of the requisite requirements could utilise their time to much better advantage. Attention was therefore directed in other directions. This had been in the form of annexes to asylums and hospitals already existing. It was first instituted at Willard, New York, by Dr. Chapin. Provision had been made there for some fifteen hundred of the various classes of the chronic insane, with some six hundred or more acres of land, which provided occupation. A somewhat similar plan had been adopted at the State Hospital at Middletown, Conn. Two annexes had been erected there-one for each sex-with capacity for 300 patients. They were in the immediate vicinity of the Central Hospital, where they were under the direct care and supervision of a separate resident medical officer for each annex, who alone decided as to the fitness of the patient to be employed. He was happy to be able to report that this plan appeared to have worked exceedingly well, so far as related to an elimination from the hospital proper of a considerable number of the chronic insane, thus providing for a like number of the acute; it provided for all that could be secured, if these patients were to be removed to houses in the country. It certainly provided for many of the chronic insane who would not be of a proper character to be boarded out. And, again, it provided for a system of care and inspection vastly more efficient than would be possible for boarded-out patients. Finally, the expense was much less than would be the case if such cases were boarded in families in the conditions of society in the United States. He regretted to say that in the hospital at Middletown there had not been separate accounts kept in the expense of providing for the two classes, so that he was unable to state what this would be. He might, however, say that it was originally thought that the expense of care of the mild chronic insane would be not in excess of two-thirds that of the more acute and excited chronic insane, but in consequence of some defect of the law such separate accounts had not been required. He desired to express his thanks to Dr. Turnbull for his very thoughtful and interesting paper.-Dr. Mould said, with reference to the distinction which Dr. Yellowlees had pointed out-namely, boarding out with individuals and families not connected with the asylum, and those who were lodged out in houses owned or ruled by the asylum authoritiesthat two-thirds of his patients-that is, about 200-were lodged out in houses in the neighbourhood or at a distance. They were under careful supervision, but were boarded and cared for by the asylum authorities, being frequently visited by the medical officers; and with such precautions the system answered well. The cost was considerable, but the effect was good. The Commissioners visited such patients, and care was taken that no patient was allowed to live in the outside houses unless they could be cared for without either danger to themselves or others.-Dr. RICHARDSON said that, boarding-out not yet having been formally sanctioned by the Legislature of the Isle of Man, it had not yet been so fully developed there as it might be. He might, however. notice one case of a male patient who was located with a farmer, He cost the asylum nothing excepting his supervision, and received from his employer a sum of $3 \mathrm{~s}$. per week in money, in addition to being fed. There was one aspect of boarding out which he had always regarded with regret-namely, that frequently it was the most useful patients who were most suitable for boarding out, and that consequently, on their withdrawal from the asylum, perhaps more paid help was required. Counterbalancing this, however, was the fact that when a useful patient was removed it was found that the attendant would generally train up another patient to take the place of the one removed, and therefore that even in this respect benefit to the asylum community ensued. -Dr. Clodston said that in the Royal Edinburgh Asylum, during the fifteen years he had been in charge of it, the pauper department had not increased, and this had been entirely owing to the energetic and intelligent system of boarding out adopted by the Edinburgh inspectors of the poor. The result of this had been that the money spent on the pauper department during that time $(£ 35,000)$ had been spent in developing hospital and admission. departments or reconstruction, and generally in making the institution more medical and more curative, and not in providing those endless annexes for incurable, mindless dements as they had had to do in the English and Scotch counties. They had 500 pauper patients and 250 yearly admissions. Therefore from the ratepayers', the physicians, and the administrative point of view, their boarding-out system had been useful. He believed the patients were well cared for, and those who turned out to be not suitable were sent back without much cost or trouble. He did not pretend to be sure about the cases that were suitable for boarding. out when he was selecting them in the asylum wards. Many cases he had thought most doubtful had turned out well as boarded-out cases, while some of those he thought most suitable had to be sent back.-Dr. WATSON said there was a danger of losing sight. of the fact that the guardians of boarded-out patients were very poor, who hoped to benefit pecuniarily by the patients, and that. they were therefore doubtful persons to whom the charge of their. lunatics should be given. For instance, according to Dr. Turnbull, in Shetland, where the people were poor, 53 per cent. of the insane were boarded out; whereas in Nairn, where the people were well-to-do, the proportion boarded out was only 8 per cent.-Dr. ROGERS considered that the question was chiefly a financial one. Where wages were high and employment constant it did not pay persons of the labouring class to take lunatic boarders. The number of patients boarded out under supervision of parish authorities, and also the number in workhouses, had materially fallen off since the granting of the weekly allowance of $4 \mathrm{~s}$. per week for lunatics in asylums, which was not extended to those in. workhouses or boarded out. This was especially marked in the last-named class, which had fallen in Lancashire since the grant was first given to one-fourth of what it was. The falling off of the number in the workhouses might be assumed to be due to this cause, because, by the addition of the $4 \mathrm{~s}$., the cost in asylums and workhouses was equalised, the guardians got rid of a troublesome class of inmates, and could utilise the space for others. Referring to Dr. Clouston's observations, Dr. Rogers wished to know if it was not a fact that the elimination of so many chronic quiet patients (such as were suitable for boarding out) not only increased the cost of those that remained in the asylum, but also, by associating a larger proportion of the more excited, destructive, and violent cases, did not increase the general excitement of the asylum wards, and so act prejudicially on those who were left behind, as patients of a quiet demented class were not only useful workers, but acted also as a diluent in moderating the turbulence of the more excited class. In Lancashire the subject had received much attention, and he (Dr. Rogers) believed that it had been. unanimously settled in favour of erecting annexes for the accommodation of the chronic class of patients in connection with each of the county asylums.-Dr. TURNBULL, in replying, argued that failures or shortcomings in the system should not be taken as implying that boarding out ought not to be practised at all. $\mathrm{He}$ believed that it was capable of being carried out in districts where at present it was believed to be impossible, or, at any rate, was not practised. He thought the remarks made by different members in the discussion showed that our general lunacy ad ministration should, like our asylums, include various modes of provision, so as to meet the various requirements of our patients, and that boarding out was one mode of provision which should be maintained, as it was exceedingly beneficial in improving the mental state of one class of the insane. Boarding out existed in all countries, and always would exist; the special feature in Scotland was that it was systematic and brought under the inspection of a central authority.

Pathology of Delusional Insanity (Monomania).-Dr. JosepH WIGLESWORTH read a paper on this subject. The importance of considering monomania as a distinct type of insanity was pointed out, and, in particular, its fundamental distinction from manis was insisted on. Mania was considered to be an affection of the highest controlling and co-ordinating plexuses of the brain, and in dissolution of the nervous system from this affection, the nerve cells and fibres perished from above downwards. But it was suggested that, in the disease known as delusional insanity, the nervolus derangement progressed, not from above downwards, but 
from below upwards, the primary change being in the peripheral nervous system or lower cerebral centres. The evidence in favour of this mode of origin was twofold, being derived partly from a consideration of the mental symptoms themselves, and partly from the teachings of pathology in allied cases. The three leading mental traits of delusional insanity were (1) the entrance of wellmarked hallucinations (or illusions); (2) the presence of delusions; (3) the preservation of the reasoning faculties. The invariable presence of the hallucinations was insisted on, and their relation to the systematised delusions pointed out. The author considered that in this affection the hallucinations always came first in point of time, and that the delusions were secondary, being directly developed out of the sensory disturbances. The direct dependence of the delusion upon the hallucination could, indeed, often be clearly traced-for example, the construction of delusions of conspiracies and persecutions out of hallucinations of the tactile and auditory senses. Here the pathological formation of ideas proceeded upon the same lines as the normal physiologicnl process. If, then, it could be shown that the hallucination always preceded the delusion, clearly the latter must be a secondary thing, and the primary change must be in the nervous structures, derangement of which was capable of giving rise to simple uncomplicated hallucinations. The preservation of the reasoning faculties was a fact of much significance. The argumentative power and excellent memory displayed by many monomaniacs was commented on; and it was argued that this fact in itself showed that, at this stage of the case, there could be no disense of the highest centres of mind. Turning to the pathologicnl evidence, the author remarked that it was a recognised fact that disease of the sense organs was prone to give rise to a relusional state ; and cases were quoted of syphilitic optic neuritis, in which marked delusions of suspicion became developed, the latter disappearing on the cure of the optic troubles. The most typical examples, however, of a delusional insanity. dependent upon changes in progress in the nerves themselves, were derived from certain cases of locomotor ataxy. The insane manifestations which at times supervened in this disease frequently took the form of the monomania of suspicion and persecution; and the importance of these cases lay in the fact that we could often clearly trace the genesis of the delusion out of the abnormal information furnished by the peripheral nervous system. The alinormalities of the tactile sense in this disease gave rise to various kinds of perversion of touch, the patients feeling as if they were treading on cotton-wool, etc. The perversions of this sense were, however, usually conducted by the sense of sight, and no delusions were developed. When, however, blindness came on from atrophy of the optic nerves, this method of correction was no longer available, and delusions were very prone to ensue. So much the more likely were these to occur if the auditory nerre also became affected. If the main avenues to knowledge were sealed, deli1sions must become developed almost as a matter of course. That under these circumstances the sensory pains should be mistaken for the tortures inflicted by supposed enemies was not surprising, nor was it to be wondered at that delusions of suspicion and persecution should become developed. Such cases showed that a mental state practically identical with monomania might be produced by physical changes in progress in the peripheral nervous system. This did not prove that the more crdinary examples of this affection were thus produced, but it suggested that at least in some cases they might have a similar origin and course. It was not necessary, however, for the lesions to be of the coarse nature of sclerosis in order to produce an effect; changes far more delicate might be equally efficacious, although less easy to demonstrate. Clearly also disease of those nerves which took the leading part in furnishing the raw material of intelligence would be more likely to be followed by mental derangements than affection of those nerves which were less immediately connected therewith. Hence the paramount importance of the senses of sight and hearing in this regard; hence also, perhaps, the comparative infrequency with which mental derangements became superadded in the numerous forms of peripheral neuritis, this affection having been studied chiefly in connection with the mixed spinal verves. It was not, however, proposed to limit the inception of delusional insanity to the peripheral nervous system; in some cases it was probable that the disease commenced in certain lower cerebral centres, such as the optic thalamus or the primary perceptive cortical centres-those forming the end stations of the nerve fibres from the special senses; post-mortem evidence in favour of this latter mode of origin was however at present wanting. $-\mathrm{Lr}$.
SAvAGE said that monomania used to be looked upon as often the result of degeneration due to mania, or more of ten melancholia. Dr. Wiglesworth preferred to consider monomania as the equivalent to delusional insanity. He (Dr. Savage) doubted whether sense perversion would produce delusional insanity in any than a neurotic person. He agreed that sense perversion preceded delusions. He met with many cases with deafness and delusional insanity ; middle-aged people developed deafness and hallucinations of hearing, suspicion, dread, and fear of persecution, and might finally become possessed by ideas of grandeur. Locomotor ataxy provided many interesting experiments of sense perversions, and was worth all our efforts at investigating the mental accompaniments. He agreed that often in delusional insanity memory and other mental faculties might be intact.-Dr. MICKLE differed from Dr. Wiglesworth as to monomania always being preceded by and based upon hallucinations of the special senses. He believed that in many cases of monomania hallucinations did not precede, whether they subsequently occurred or not. In some cases of monomania there were no hallucinations at the onset; there was often disorder of the inward feeling-a perversion of the normal feeling of existence.-Dr. CoNOLLY NoruaN said that it appeared to him that monomania frequently occurred without hallucination. He thought the disease was essentially a degenerative one, arising most often in the hereditaril 5 disposed or those who had acquired a predisposition. It was akin to idiocy; it also often followed on neurasthenia. This might in part account for its tendency to be associated with tabes dorsalis, the same cause underlying both. Its distinctive clinical features he held to be a tendency to systematised and organised delusion with relative integrity of the higher intellectual functions. He instanced cases in elderly men of systematised delusions of conjugal intidelity. It must be remembered that the integrity of the higher functions was only relative. The highest function of all, the judgment, was profoundly impaired. Believing, as he did, that monomania was a disease that could hardly be acquired by a brain that had not been abnormally constituted for a length of time, he could not accept Dr. Wiglesworth's views. Dr. Norman referred to the investigations of Dr. Charles $K$. Mills, who held that the brains of monomaniacs showed certain peculiarities of conformation-undue width of the Sylvian fissure, deficiency of the annectant gyri, prolongation of the parieto-occipital fissure over the external surface of the hemisphere, etc. Such profound and essential alterations in the conformation of the brain wert rather, perhaps, what one would expect, considering the essential nature of the malady.

Relations of the Sexual and Reproductive Functions to Insanity.-Dr. CAMPBELL CIARK introduced a discussion on this suliject, and suggested subjects for discussion under the heads of : 1. Ilenstruation. 2. The sexual instinct and its abuse. 3. Pregnancs, parturition, the puerperal period, and lactation. The question of action and renction of body and mind opened up the subject; next came the question what had menstruation to do with mental change and mental disease; and the relation of amenorrhcea as a cause or sequence of mental disense. The neurotic relations of chlorosis were touched on, and special attention was given abnormalities of sexual development in cuses of insanity. The study of the sexual instinct assisted by temperature registrations, the effect of different diets, and the relations of self-abuse and insanity were next considered. I rare type of trophic disease associated with masturbation was described, and the question was asked: Is there such a thing as true masiurbatic insanity? When is it primary and when secondary? And lastly, the influence of the act of masturbation directly in the mentil condition, especially in producing violence, excitem: nt, and attempts at escape. In opening up the third section, attention was specially desired for topies which give scanty information in individual practice, so as to accumulate evidence of rarir kinds. of such the following were proposed: 1 . The nervous and mental peculiarities of pregnancy. 2. The mania transitoria of labour. 3. Puerperal eclampsia associated with insanity. 4. The premonitory symptoms of puerperal insanity. Clinical illustrations were given briefly of insanity of pregnancy, the munia transitoria of labour was referred to from the author's experience, and the re'intive signiticance of the various premonitories of puerperal insanity was also stated.

Mental Disorders associated with Marriage Fingagements.-. Dr. GeorciE II. S.IVAGE said that cases of mentul disorder associated with marriage engragements were frequent in both sexes. In many it was only a natural feeling or set of feelings in excess; 
it was not necessarily associated with habits of masturbation, nor was it necessarily associated with continence, though in some cases excess and in others abstinence seemed to be part causes. The onset of the disorder was often rapid, might be sudden, it wes always of a melancholic type, there was self-analysis and vor self-consciousness, frequently loss of or change in affection, with or without religious depression; these symptoms often led to breach of promise of marriage and might be connected with legal actions; these affections were more common in neurotic families and might occur to the same person several times, and might occur in several members of the same family. As a rule these cases rocovered under proper care. Marriage or sexual indulgence should not be recommended; it would often lead to ideas of impotence and suicide.-Dr. Clouston said it would be necessary to unite the experience and knowlenge of general practitioners of medicine and gynrecologists to have a satisfactory discussion on the most important subjects so very ably treated by Drs. Campbell Clark and Savage. The mental symptoms of puberty and adolescence could not be dissociated from the headaches, the chloroses, the choreas, the epilepsies, and the trophic deficiencies of the period. All this came from the same cause-a want of full developmental force in highly-organised and hereditarily weak brains. The connections of disturbed menstruation and insanity might be divided into two, the acute mania of sudden suppression and the melancholia of amenorrhœa and menorrhagia. In regard to the causative connections of masturbation with insanity it comprised, in a sentence, the neurotic. Youths might become insano from masturbation. The strong country lumpkin might masturbate as much as he liked and no permanent harm would come of it. He advocated paraldehyde for sleeplessness as the very best hypnotic we had, whether there was mental disease or not. And whenever they had a highly-temperatured and puerperal insanity large doses of quinine (10 to 20 grains), frequently repeated, was by far the best remedy.-Dr. WiGLESworTh said that with reference to the question of association of puerperal insanity to septicnmia, he should like to bear witness to the fact that $n$ large proportion of cases of mania arose in connection with this condition. As regards masturbation and insanity he should have liked to have heard more remarks about masturbation produced by insanity. He had very frequently seen temporary masturbation in epileptics after their fits-in patients who were in all respects correct at other times; and he thought, in a large number of cases, masturibation mas the effect of insanity and not its cause.Dr. CAM PBELl (Garlands) thanked Dr. Savage for his very excellent paper, but confessed his entire inability to discuss such a paper without further consideration. Such a paper should be carefully read before it could be discussed. As regards some of the remarks made by Dr. Clouston, Dr. Campbell said his puerperal cases rarely slowed any signs of septicxmia. The temperature rarely kept up for any time; his experience, as given in the paper of Dr. Macleod of Beverley, had been very fortunate in puerperal mania. As regards reduction of temperature by large doses of quinine, Dr. Campleell questioned the benefit to the patient, and this after largely using the treatment in a considerable number of cases of pneumonia. Ife had used paraldehyde pretty largely. II thought it one of the best hypnotics we had; its taste was against it, but if given in rum this was not noticed. He had also used urethane, but did not think so highly of it.-Mr. ArFRED APLIN rose to seek information respecting the connection between selfabuse and true ozæna. It was stated in another Section yesterday that oziena was a very constant accompaniment of this vice, especially so in women. During his twelve years' experience of asylum practice he hud met with numerous cases of hallucinations of the sense of smell, but never with true ozena, except in a few cases which were due to syphilis or to injury to the nasal bones. -Dr. Tulisel li referrel to a case associated with amenorrhœa of long standing. in which the use of permanganate of potash had proval of service, and in which the patient ultimately recovered : and to a case of an epileptic youth, who averred that the act of masturbation gave great relief to the feelings of heaviness and confusion in the head which came on him periodically. He mentioned also the case of an epileptic woman, who had at one time intense suicidal impulse, and attempted to cut off her head; she afterwards married, and during her pregnancy had an attack of very acute mania; she was quite delirious during the birth of her child, but immediately afterwards improved very rapidly, and soon recovered from the maniacal state. His limited experience of paraldehyde had so far not been so favourable as Dr. Clouston's, but he would give it a further trial.-Dr. SAvAGB said there was no evidence that anenorrhoea depended in any way on insanity causally. In some cases obstinate amenorrhou followed with mental weakness. In puerperal insanity he recommended a return to domestic life, with precautions against pregnancy. He believed masturbation in boys and girls might arise epontaneously. He had had a graphic description of this by a female patient. At the climacteric and at other ages, with sexual perversion there were often hallucinations of smell, and Sir A. Mitchell recognised this. He had found salix nigra useful in some cases of masturbation, but it was not useful in many weakminded young men. Its effect was useful in some who were able to feel disgust, and sermons and salix nigra were both useful in these cases. He saw a good many cases of insanity of pregnancy, and he divided them into two classes-those before the fourth month, which generally got well at "quickening;" the other went on to insanity of parturition. Transitory mania was of very great medico-legal interest. Women might be unconsciously delivered. He had known same cases following eclampsia, but most of those reported were hysterical. He looked on sleeplessness and bad dreams as early symptoms and very general. He had seen septic causes giving rise to puerperal insanity.

Asylum Construction. - Dr. Clouston (Edinburgh) read a paper on the principle of construction and arrangement of an asylum for private patients of the richer classes. He said that in every good institution a strong effort was now made to make the accommodation for every class of patients homelike, cheerful, and tasteful, and to provide a variety of accommodation to suit patients in different states of mind. This idea was given effect to by different physicians in different ways, but in all cases with the object of the cure, contentment, comfort, and health, bodily and mental, of the patient. The house in which he lived, and the impressions made on his mind of his surroundings, were universally admitted to aid most powerfully the direct mental treatmentthe diet and the regimen, the nursing, the moral means, and the amusements and occupations, in the recovery of a mentally afflicted patient. The chief varieties of accommodation that should be provided for the better classes were five, namely: (1) special wards near the medical officer for the treatment of the acute cases, the very suicidal, the disorderly, the violent, and those needing much supervision from any mental cause; (2) infirmary wards for the weak, the paralysed, the very old, those deprived of theirsenses, the sick, and those requiring much and careful bodily nursing; (3) houses attached by corridors to the administrative centre, mostly with arrangements much like those of an ordinary house or an hotel, each containing a distinct group of patients, whose home it is, but with certain special arrangements ; (4) cottages and villas within the grounds; (j) seaside and country houses, where bathing, fishing, and change of air and variety of life could be got. The three last were specially suited for the patients who were improved in mental state, for the convalescent, and for many chronic but quiet cases, who could enjoy with safety and be benefited by home-like surroundings and change of scene. The hospital home for the insane should be constructed on the principle of adaptation of varicus parts of the house to the varied needs and mental states of its inhabitants. That meant much rariety, but the more he had found that principle carried out the happier did the patients seem, and the better were the results in recovery and financial success. His general conclusion was that they should proride about 45 or 50 per cent. of their accommodation in the shape of central wards, 25 to 30 per cent. as houses attached by corridors, about 14 per cent. as infirmaries, and 15 per cent.. meantime, as attached villas in the ground or as country or seaside houses. Dr. Clouston proceeded to describe plans that had been drawn for the construction of an asylum for 150 private patients in the neighbourhood of Edinburgh, in which the ideas promulgated in his paper had been carried out.-Dr. IRQLHART then described two infirmary wings that were in process of erection at Murray's Royal Asylum, Perth.Dr. CAMPBell (Garlands) questioned very much if most rich cases could not be treated in private houses quite as well as in an asylum. He might remark that all asylum officials should know that. A cement now made at Carlisle by Robinson and Co. was, for its price; the best and most useful thing for an asylum. IIe quite disagreed with the Scotch plan of wood lining walls in asylums; it was dirty, offered a habitation for both fæces and insects, and increased the risks of fire. He thought both commissioners and asylum superintendents had been foolish in going so much in for this wood pannelling. He thought cement walls were, for health, cleanliness, and all purposes, much better than any 
mode of wood mural adaptations.-Dr. WARD said he would have been glad to have heard from Dr. Clouston some details as to lighting an asylum by electricity, and the relative cost of that to gas.

Methods of Examining Children in School as to their Development and Condition of Brain.-Dr. Francrs WARner read a paper designed to show that it was practicable to examine the children in a school as to their development and brain-state by visible signs observed. Two classes of signs were described: $a$. The proportions and form of the body, the head and the separate features, obvious bodily deformities or signs of disease, and the signs of nutrition; $b$. The movements and balances or postures of the body and action as seen in the face, the eyes, and other parts, typical forms of which had been described and classified by the author. Thus the signs indicating nervousness, exhaustion, frequently recurring headaches, or slight chorea, had often been detected in school children, as also the signs of low-class brain action. Examples were given of facts seen when observing children in schools, and cases were quoted showing that in many instances visible defects were found to correspond with defects in character. The author urged that attention should be directed to these cases, that means should be taken to ascertain their proportion among strong and healthy children, and concluded by moving the resolution already published in the Journal (p. 373).-Dr. SHutrLEworTh rose to second the resolution proposed by Dr. Warner. He trusted the importance of the subject of Dr. Warner's paper would commend itself to the careful consideration of the Section. It was, of course, impossible in the few minutes remaining that morning to adequately set forth the physical criteria upon which the skilled observer might form an opinion upon the fitness or otherwise of children in elementary schools for the prescribed curriculum; but it would be readily acknowledged that a certain percentage were seriously handicapped by defect of nerve power, which expressed itself in physical abnormal conditions, for example, chorea, and certain allied movement disorders. There were, no doubt, many children who were not so deficient as to be called idiots or even imbeciles, but were nevertheless so far below the average of the mens sana in corpore sano, that they were left out in the cold under our present educational system. It was with a view of investigating in a scientific manner first the number and then the needs of this class, that Dr. Warner had brought forward his resolution. Not long ago Dr. Shuttleworth had been interrogated by the Royal Commission inquiring into the education of the blind, deaf-mutes, imbeciles, and other exceptional children as to the desirability of doing something for the class to which Dr. Warner had referred. The assistance of the British Medical Association, in whose JourNaL the matter had been already discussed, would be of great moral weight in drawing public attention to this matter, and it seemed only fair that the necessary expenses connected with the inquiry should be defrayed by a grant from the Scientific Investigation Committee. Dr. Shuttleworth concluded by describing the so-called "auxiliary classes" for abnormal children which he had seen at work in Norway in connection with the elementary schools, and which existed also in Germany. -Dr. HACK T'UKE supported Dr. Warner's motion. Having recently seen the intermediate or auxiliary schools in Germany, he (Dr. Tuke) believed them to be very useful; and he could see no better way of ascertaining whether there was a sufficient number of the class of cases in question than by appointing a committee to make careful and extensive inquiries in elementary schools.Dr. Yeliowleses thought this was only a part of a far larger question. He was less concerned for the small proportion of manifestly nervous children, whom any good teacher would recognise and deal considerately with, than he was for the great mass of ordinary children in primary schools, whose growing brains were crammer with all sorts of knowledge, and all crammed alike, in a way that was an outrage on physiology and common sense. He would like, if possible, that the scope of the Committee's investigation should be extended so as to include this supremely important subject.-Dr. Fuetcher BeAch supported Dr. Warner. He thought the proper method was to observe physical signs. They all knew how doctors were said to differ in their opinions. If we gave an opinion that a child was weak-minded, that was only our own opinion, and might be contradicted; but if skilled observers noticed physical signs, and limited themselves to this, there would be more confidence in the observers on the part of the public. There was no doubt that the teachers of schools would be glad of such medical help. Some time ago, a case arose in the School
Board for London, in which a father wished to send his child to school, but the teacher refused to admit the child, saying she was imbecile. He (Dr. Beach) was sent by his chairman, who was then on the School Board, to see the child and give his opinion. On entering the house, he saw at once that she was a Mongolian imbecile. He gave a certificate to that effect, and both parties were satisfied. Afterwards he wrote to his chairman, suggesting that day schools for the feeble-minded should be formed; that the children should not be sent to asylums, but that the homelife should be kept up; and that the child should go, if possible, in charge of another child, and return in the same charge when the school was over. Unfortunately, his chairman soon after left the School Board, and nothing was done. If countries like Norway and Germany had day schools for the feeble-minded, surely a country such as England should also have them.

Cases of Disease of the Brain in Imbeciles.-Dr. FletCHER BrACH said that actual disease of the brain was not so common in imbecility as want of development. It was more usual to find the convolutions simply arranged than to find tumours, hydrocephalus, sclerosis, etc. The convolutions in some cases were quite half an inch in width, and in such cases the arrangement must necessarily be simple. The two conditions producing undue size were hydrocephalus and hypertrophy of the brain. Hydrocephalus might be present at birth, or come on afterwards. The shape of the head in hydrocephalus was different from that found in rickets, and the differences were given. Hypertrophy of the brain was a comparatively rare disease, and its cause was obscure. The process was not one of mere increased growth, but the nutrition of the organ was modified in character as well as increased in activity. According to Rokitansky, the augmented bulk was not produced by the development of new fibrils, or by the enlargement of those already existing, but by an increase in the intermediate granular matter, most probably due to an albuminoid infiltration of the structure. MM. d'Espine and Picot considered the affection to be a congenital one, and in this opinion as well as that of Rokitansky the author concurred. The principal symptoms were headache, at times intensified, excitement followed by coma, blunting or arrest of development of intelligence, difficulty in walking, and convulsions. Tables showing weight of hypertrophied brains, and average weight of brains of individuals of the same age were distributed, and the differential diagnosis between hydrocephalus and hypertrophy was given. Atrophy of the brain was due to incomplete development, or to loss of nervous elements which had previously been present. Microcephalic imbeciles were instances of the first class. The nerves of special sense were usually well developed in microcephaly, and the ganglia of the base and of the spinal cord were of nearly normal size. The cerebellum was relatively much larger than in the normal brain. The second form of atrophy might present itself in various forms, but the most interesting was that in which there was atrophy of one side of the brain, usually the left, with coexistent atrophy of the limbs on the opposite side of the body. Imbecility was not necessarily the result, everything depending upon the more or less healthy state of one hemisphere of the brain. In inflammation of the brain meninges or skull during fœetal life or early childhood would no doubt cause the disease. The course of events appeared to be this: first, there was, as the result of chronic inflammation of the meninges or of the cortical substance, wasting of one side of the brain. To compensate for this, the skull became thickened, and serum was poured out beneath the arachnoid and into the ventricles. Then, since those parts of the brain which were connected with motion were wasted, the limbs, the action of which was governed by them, were imperfectly nourished and became atrophied.

Clinical Results of Craniometry and Cephaloscopy in Diseases of the Mind and Brain.-Professor BENEDrKT (Vienna) gave a most interesting demonstration on this subject, copiously illustrating his arguments and conclusions by skulls, drawings, and sketches on the black board. He insisted on the hereditary influence in development, and described the divers shapes of the skull from the point of view of symmetry, compensation, and accurate measurements. In cases of anomalies of the brain functions, either congenital, hereditary, or acquired in early youth, Professor Benedikt said he inquired whether the skull and the head were normal or not, and on the other hand, when a skull or head was found abnormal, he asked if the brain functions were in order. He gave a short summary of his results, which are published largely in his new book (Craniometry and Cephalometry, Vienna, 1888, Urban and Schwarzenberg). In general, excessive measure- 
ments were equivocal, as they might represent either perfection or degeneration. On the contrary, extreme deficiency in the measurements was generally quite unequivocal. This was especially the case as regards undue smallness of the skull and head in general, and of the shortness of the median and transverse frontal, parietal, and occipital arches. Taking oxycephaly as an example, he showed how Nature endavoured to compensate partial deficiencies, and how this work of compensation could produce very atypical shapes, which might thus come to lose their pathological significance. He also referred to the lower forms of trigonocephaly and their great clinical importance; to a sort of "pecten" in the anterior part of the sagittal suture; to the importance of abnormally low skulls; to extreme dolichocephaly and brachycephaly; and to asymmetry principally through defective evolution of one-half of the skull. Professor Benedikt attached great clinical importance to that form in which the ears were too near to the posterior end of the skull (brachycephalia occipitalis bilateralis), and to another type in which this was the cuse only on one side (brachycephalia occipitalis hemilateralis). The last anomaly was the most frequent anatomical symptom of degeneration of all sorts. In studying the details one learned how intimate were the relations between anomalies of form and anomalies of brain functions. These researches were not matters of opinion, but solid facts.-Professor GaIRDNER expressed the wonder and gratification of the meeting at the researches of Professor Benedikt.-Dr. BatemaN (Norwich), after expressing the great interest he took in the subject brought under the notice of the Section, said that Professor Benedikt had given the result of his microscopical examinations, by which he found that each section differed microscopically, and therefore proved difference of function. $\mathrm{He}$ (Dr. Bateman) would like to ask Professor Benedikt whether he had made any chemical examination of different sections to ascertain whether different regions differed chemically. He thought that the chemistry of the brain had hitherto been much neglected, and that its study was calculated to throw additional light upon the obscure question of localisation of function.-Dr. BATTY Tuke said they were a long way from the point where chemistry could assist. As allusion had been made to the character of cells, he wished to mention that he had commenced a series of examinations of brains of persons dying from all sorts of disease. The result showed that in exhausting disease rapid degeneration of cells took place; that in such diseases as pneumonia the great cells of the third layer were as extensively degenerated as in the oldest cases of senile dementia. A long series of observations was necessary before even the roughest generalisation could be ventured on. The first step should be the establishment of a typical healthy cell.

Hallucinations.-Dr. HACK TUKE read an elaborate paper on hallucinations, arriving at the following conclusions. 1. That the revival of a sensory impression in idea did not call into action any infra-cortical sensory organ or nerve. 2. That when this revival was so intense as to induce hallucinations, but yet they were not projected externally, there was still no reason to assume more than an intensely vivid action of the cortical cells representing sensory impressions. 3. That even when these hallucinations were projected outwardly, there might be in some instances no action of the peripheral sense organs and nerves, but there might be in such eases a backward current as far as the sensorium. 4. That the proofs of the peripheral sense-organs being sometimes involved, even when this hallucination originated in the cortex, were very forcible. For example, in visual hallucination, if the object seen followed the motions of the eyes, concealed real objects, and was projected, the presumption was in favour of this view. 5. That Brewster's test of the subjectivity of an object alleged to be visible was, in his own experience, reliable.-Professor BALL (Paris) stated that he had observed the fact of double vision in hallucinations by pressure on the eyeball, not once, but a great many times; and this occurred exclusively in cases of hypnotism or of natural somnambulism.-Dr. A. RoBERTSON said that the threefold course of hallucinations was-1, from the sense organ; 2 , from the lower ganglia ; 3 , from the cortex. The more perfect the hallucination the more likely was it to be of cortical origin. A personal experience was suggestive of the mode in which hallucinations might arise and spread. Seven years ago, owing to inflammation of the eye, a friend put a few drops of a solution of nitrate of silver into his (the speaker's) eye. Whether his system was specially susceptible at the time, or the inflammation was too acute for the application, he did not know, but it produced most marked effects.
First, there was intense pain and spasm of the eyelids, with flow of tears; then there was the appearance of balls of fire being projected before the eyes at momentary intervals, and thereafter there seemed to be frequent discharges of artillery; these were accompanied by a feeling of severe strain. What occurred was 1 , there was the ordinary reflex spasm; 2, there was an extension from the optic to the auditory centres, possibly in the lower centres, as the false impressions were of so simple a kind. In the cortex we might have similar origin and extension of hallucinations. In this connection it was interesting to remember the close proximity in situation of the auditory and visual centres. This might perhaps explain, or at least it suggested, how often in acute insanity, hallucinations of sight and hearing occurred together, or the one after the other. Alcohol might act, as it often did, on one part of the cortex more readily than another in different cases, owing to the peculiarity or imperfection of development; hence visual hallucinations might be prominent in one case, auditory in another; and the same remark applied to other agents and morbid causes. - Dr. IRELAND said that he could not agree with the view that in hallucinations there must be disease of the sensory cortical centres. Binet and others had described cases where the hypnotised subjects saw their hallucinations divided by a prism or reflected in a mirror; but a rigid examination of these cases had proved that visual hallucinations were not really governed by external optical conditions. They were the result of ideas either suggested by the hypnotiser or caught up by the hypnotised person. A good hypnotiser could cause his subject to make any kinc of observation he desired to bring out.-Dr. BATTY TUKE said one source of hallucination had not been alluded to, namely, the actual, wilful false statements of the hysteric. As he or she invented false statements as to facts, false statements were made as to things seen, heard, or felt, in order to arouse sympathy or interest. The utmost care was required to be exercised in inquiry into such statements, and even the utmost care could not entirely guard the inquirer from being deceived.-Dr. YelcowLEES agreed emphatically with Dr. Batty Tuke, that many emotional persons gave quite untrustworthy accounts of their alleged hallucinations with a view to excite interest and attention, but he desired to call attention to another large class whose apparent hallucinations were only vivid descriptions of their vivid recollections, who unconsciously deceived themselves as well as others, and whose personal equation-a very large one-had to be deducted from all their statements of their personal experiences. He fully believed in the cortical character of all true hallucinations.-Dr. SAVAGE said many people could visualise voluntarily; this was purely cerebral, and there were many insane who thus visualised. This visualising was not necessarily associated witb disease of the cortex. Other cases were hallucinated through disorder of organs of sense. The alcoholic and the tabetic might interpret their morbid sensations as hallucinations.

Four Cases of Folie à Deur in the Same Family.-Dr. Oscan T. Woons read a paper on four cases, undoubtedly of communicated insanity, exhibiting all the symptoms of folie $\dot{a}$ deux, as described by Dr. Hack Tuke. The sudden onset of the attack of those secondarily affected, the similarity of the delusion and the symptoms in each case, the quick recovery and the family history were all interesting features. Five members of one family (mother, son, and three daughters) were recently admitted into the Killarney Asylum, under the following circumstances. On the day previous to admission, the constabulary found all these patients in their house, almost naked, fighting, screaming, and behaving more like wild beasts than human beings, and the dead body of a child, the son of the eldest lunatic, lying on a dungheap in front of the house; further inquiry revealed the fact that this child had been murdered. It appeared that during the previous night, at " cockcrow," the mother took the boy, aged 14, out of the house, and beat his skull in with a hatchet, and then, as they all with one accord described it, "We prayed and went to Heaven." The eldest daughter was the first insane, having for some days been very excited, all the other members of the family affected appeared to have become suddenly insane on this fatal night. The one dominant delusion with all was, that having killed the fairy, they were freed from their sins and went to Heaven. The family history was peculiar, for while the father of this family, and one of his brothers, married strangers, nearly all their children were either insane, or deaf and dumb. Another brother, who married a first cousin, had brought up a family all perfectly healthy. The only hereditary taints on either side were, an uncle of the mother's 
died insane; a first cousin of the father's had recently committed suicide. The result was also interesting, as all those secondarily attacked recovered within a fortnight, while the eldest daughter, the one primarily insane, was still demented, and showed no sign of improvement. An hereditary predisposition, together with strong superstitious ideas, acting on people whose bodily health was impaired by bad food and loss of rest, must be assigned as the causes of the attack.

Note on Antifebrin.-Dr. W. Jurus MickLE read a paper dealing with the antipyretic properties of antifebrin, as administered to various insane patients, particularly those suffering from pulmonary phthisis; and referred to the state of the patients both generally and as regards the local lesions at the time of the administration of the drug, and the temperature charts as influenced thereby.

\section{SECTION OF OTOLOGY.}

Wednesday, Thursday, and Friday, August 8Th,9Th, and 10Th. Cerebral Abscess from Ear Disease.-After delivering his address, which is published at page $472, \mathrm{Dr}$. BARR (the President) showed two cases which had been operated upon by Dr. Macewen for cerebral abscess due to ear disease. The first was a boy, aged $10 \frac{1}{2}$, who had been operated upon on January 22nd, 1887. For a year previously there had been a discharge from the ear. Prior to the operation he had been ill for about a month with romiting, rigors, headache. slow pulse. Three days after admission to the Ear Hospital, Dr. Barr perforated the mastoid process, and washed out the middle ear with a disinfecting solution. This operation was followed by no distinct subsidence of the symptoms, and Dr. Macewen then trephined the skull. A half-inch disc of bone was removed from the squamous portion of the temporal bone at a point an inch and a half above and half an inch behind the centre of the external auditory meatus. A hollow needle was inserted into the brain, and, after it had penetrated the brain tissue for about three-quarters of an inch, there was a sudden escape of foul gas, followed by abuut two drachms of offensive, yellowish-coloured pus, while shreds of sloughed brain tissue were removed by the forceps. To ensure perfect drainage, a second aperture was drilled just above the external auditory meatus. Chicken-bone drainage-tubes were inserted. The parts were dusted over with boracic acid, and covered with sublimated wood-wool pads. The wound was only dressed once a week, and at the end of six weeks it was quite healed. The ear-discharge was also completely at an end, while the hearing distance was $\frac{5 \frac{1}{2}}{40}$. Bone conduction was good, and there was an excess of air-conduction. A soft depression marked the position from which the disc had been removed. The second case was that of a young man, aged 21, who was operated upon on the 15th of May last. There had been a discharge from the left ear for eight or nine years. For three weeks before the operation the symptoms were headache, vomiting, slow and intermittent pulse, normal or subnormal temperature, contraction of left pupil, paresis of all the ocular muscles with exception of the external rectus, partial facial paralysis on the opposite side, paresis of right arm, with wrist-drop. The mastoid was first trephined, so as to establish communication with the external auditory canal, but little or no pus was found there. Dr. Macewen then trephined above the external auditory canal, and pierced the brain-tissue with a trocar. Three ounces of horribly fotid pus were removed. The cavity was syringed with a weak solution of carbolic acid. A chicken-bone drainage-tube was inserted. The dressing was not removed for three weeks, when the wound was found to be almost healed. The patient recovered without a single bad symptom. The opening was blled up with firm bone, and the patient was now perfectly well.

Perforation of the Mastoid.-Dr. P. MCBRIDE read a paper on this subject, which is published at page 474.-Dr. STEwarT (Nottingham) said he should lay it down in a general way that, with local indications of pent-up secretions in the middle ear causing injury to the general health, and not yielding to other methods of treatment carefully carried out, the surgeon should penetrate the mastoid and establish a communication through the antrum mastoideum and the external meatus. The operations short of reaching the antrum, though in themselves frequently of great benefit, were of secondary importance. He had laid down rules for his $Q$ Wn guidance for penetrating to the antrum mastoideum, and he hoped they would be found safe and reliable. If a line were drawn in the direction of the zygoma, and exactly coinciding with the osseous roof of the external meatus, and another downwards from that line at right angles to it, and exactly coinciding with the posterior osseous wall of the meatus, the posterior angle formed by these two lines would indicate the spot to be perforated. The perforation should be done as close up to these two lines as possible, but not beyond them. Let him compare these directions with other methods. The bony points being thus fixed upon, the incisions in the integuments should be guided accordingly. Bearing in mind the structures likely to be injuredlateral sinus, dura mater in the floor by the cranial fossa, facial nerve, and external semicircular canal-he believed it possible for the surgeon who proceeded with due care to expose the dura mater without injuring it or without bad consequences to the patient. Beyond a fixed depth (five-eighths of an inch) the surgeon should not go, and it was well known that in many skulls it would not be possible to bring the operation to a successful termination. The instruments that appeared to him to be the best were a trephine in preference to the chisel and mallet, sponges of two or three sizes, and a scoop. Dr. Stewart concluded by referring to some cases that had come under his own care.

Congenital Ear Disease, producing Mastoid Abscess and Facial Paralysis.-Dr. Charles WARDEN (Birmingham) related the following case :-“D. K. M., aged now $2 \frac{1}{2}$ years, of strumous aspect; light blue eyes, widely dilated pupils, and generally anæmic; born very quickly and without difficulty; father very nervous and excitable, having had a railway accident; mother nervous and delicate, had another child previously quite strong and healthy. During her pregnancy the mother was in a low nervous condition; suffered from a severe cold and intense neuralgia, which existed for some time, and affected the left side of her head and face, being the same side as in the case of the child's affection, the facial nerve being implicated. After birth the child was fretful, evidently suffered from pain; nervous and excitable, starting at the least noise; was badly nourished, and wasted in flesh. About the time of commencement of teeth formation the mother noticed a discharge from the left ear, after a feverish attack, restlessness and distressed condition, generally followed, in a short time, by severe convulsions, producing paralysis of the left side. After recovering from the acute symptoms she was brought to me at the suggestion of her medical attendant when about three months old, and I found her suffering from a purulent discharge from the left ear, of offensive odour and profuse. She could not close the left eye, which remained always open during sleep and at other times, and she had a constant flow of tears from that eye, in laughter and crying; mouth was drawn, cheek dropped loosely, and facial muscles did not act on that side. The discharge continued, and in about a fortnight after this the mother brought her again to me, and I found that a large abscess had formed at the back of the ear in the temporal and mastoid region. This $I$ at once opened, and diseased bone was evident. The child was treated according to the usual modes-cod-liver oil, iron, etc.; on the tonic plan, with all the nourishment it could take. Great improvement in all respects followed, and in another two or three weeks the inflammation and abscess had subsided. The discharge continued from the meatus, no direct efforts being made to check it for fear of a repetition of internal mischief. I removed some pieces of dead bone from the meatus, previous to which there was bleeding from time to time. The discharge now gradually diminished, the facial paralysis rapidly improved, no further pain occurred; the limbs were never affected, and the child walked well at $1 \frac{1}{2}$ year old. July 17th, 1888: Face now perfect, eyes close completely, mouth opens and closes with equal lips on both sides, all the facial muscles act with perfect symmetry and harmony. The child is thoroughly well nourished, talks and walks well; pupils of eyes equally dilated, but still some otorrhœa. I am of opinion that in this case a low form of inflammatory action was going on from birth. The child appeared, according to the mother's account, always in pain, whining, pining, and fretful, crying out with a plaintive cry now and again as though in paroxysms of pain, misunderstood by the parents, as is frequently the case in early inflammation of ear disease, and until the real interpretation was afforded by the appearance of the discharge. At length the teething period arrived, and then the whole condition of the parts implicated was much aggravated. The facial branches of the fifth nerve became involved, and the discharge no doubt found its way to the membrane of the brain, and possibly an 
abscess formed under the dura-mater, pressing on the brain itself and caused paralysis of the branches of the facial nerve to the eyelids, mouth, tongue, and muscles of the whole of the left side of the face. There was no evidence of its haring caught cold at birth, but that a low form of inflammation existed from the first, possibly associated in some mysterious way with the condition of the mother during pregnancy. I do not, bowever, pretend to offer any explanation, but $I$ am anxious to learn from my distinguished confrères present their experiences, and any light which may be shed on the subject. In conclusion, was there any syphilitic taint? I was disposed to look for a cause in that direction, but was quite unable to trace any such history. Was it tubercular? Had the mother during her pregnancy an attack of non-suppurative inflammation of the middle or internal ear or of the nerve structures, which was mistaken for neuralgia? I remember another case which occurred in very early life, which ended fatally, and at the post-mortem examination complete disorganisation of all structures of the middle and internal ear had been brought about, and a cerebral, or rather cerebellar, abscess was found. The history, course, and satisfactory termination of this case, considering the fact that the mischief must have commenced with life, induced me to venture on bringing it before the Association, hoping that the members present will consider it sufficiently interesting to command their attention and comments."-Dr. BARR referred to the propriety of opening into the antrum for the cure of those cases of chronic suppurative inflammation of the middle-ear which had resisted all other methods of treatment, where, in spite of long-continued and thorough cleansing and antiseptic treatment from the direction of the external auditory canal and Eustachian tube, the purulent discharge still continued and still emitted the odour of decomposition. By this means they might efficiently change the cavities of the middle ear, and bring about an end to the secreting and decomposing process, and thus the removal of a serious menace to life itself. Dr. Barr believed that in this direction important work might be accomplished in the future. The desideratum was that an absolutely safe method of operation should be adopted. Dr. Barr did not think that operation by the mallet and chisel would insure the safety of the lateral sinus, if that sinus had an abnormally outer and anterior position. The blows of the mallet were very considerable, especially in cases where the symptoms pointed to the possibility of cerebral abscess or meningitis, while to use chisel and mallet at the bottom of a deep wound was often very difficult. A proper dental burr, propelled by a suitable mechanism, was probably the safest instrument; was much easier than the chisel and mallet, and had not the dangerous points of the ordinary drill or trephine.-Dr. LACRENCE TuRnBuLl (Philadelphia) said his experience with boric acid extended back to the year 1879 , and he had not found it to act injuriously, or prevent pus from passing out. He had even packed the diseased meatus, especially in large perforations, with no injurious results, if carefully watched by the physician. Now and then an imperfectly prepared powder was employed, not having the soft soapy character, and even containing bacteria and other injurious matters, and it should be carefully treated before being used. He was of opinion that they were apt to neglect the importance of constitutional treatment in mastoid disease such as diet, rest, use of antipyrin, aconite, iron, and iodine, and, above all, the relief of pain by morphine and atropine. Polypoid growths in a large majority of old cases should be removed, for dead bone was so often found under them. In illustration of this subject, Dr. Turnbull reported cases in which he had removed sequestra of bone from the mastoid and labyrinth, which had been covered up by the polypoid growths. He also gave an account of a case of temporary insanity following mastoid disease, in a man, where there was a hard, almost ivory-like, condition of the bone, which he removed, but did not enter the antrum, and by this operation and constitutional treatment the case recovered.Dr. LEwIs (Birmingham) said cerebral abscess following suppuration of the middle ear was more frequently met with than was generally supposed. Five cases of death from this cause had come under his notice in five years; in two cases a post-mortem examination was made, when in one a large quantity of pus was found in the temporo-sphenoidal fossa; the other case died from phlebitis of the lateral sinus. Two declined treatment, but the third, who suffered from old mastoid trouble, died, he was told, from symptoms of cerebral disease. Pain was not always to be the guiding condition that demanded either trephining the mastoid or skull, for a case came under his notice where most violent pain lasted for a considerable time. All operative treatment was deferred, and the iee-bag being applied for weeks, the patient made an apparent recovery. When, after cutting down upon the mastoid caries, that condition was found, he thought the mastoid should then be drilled; and, in one case, not having a drill at hand, he had used a gimlet with satisfactory result.Dr. WALton Browne (Belfast) referred to cases of caries of the mastoid process, and advocated free drainage by suction and passing a drainage-tube through the mastoid process to the external meatus. He detailed two cases of abscess of the brain treated by trephining; one of these recovered. Dr. Browne did not approve of a drainage-tube in case of abscess of brain, and thought trouble was produced by it and washing out the abscess cavity. He would advocate simply trephining, opening the abscess and allowing it to drain away.-Dr. WALKER (Pollokshaws) bore testimony to the advantage of efficient drainage in mastoid abscess, and alluded to cases shown by him in the practice of Professors Lucae and Trautman, of Berlin, in which drainage by tubes, and also clearing out matter by suction through the meatus, was adopted with marked success.-Dr. FARQUHAR MATHESON spoke of the frequency of mastoid inflammation, and concurred in the classification of dividing this condition into two classes, namely, periostitis of the mastoid and ostitis of the whole bone. The first class was by far the most important, and occurred as a rule in children and young persons. This condition readily yielded to treatment. In the first outset leeches and fomentation were all that was required. This failing, incision through all the structures down to the bone must be made, followed by drainage. In ostitis, occurring oftenest in adult and old age, the trephine must be used to open the mastoid cells.-Mr. J 1 MES BLACK expressed pleasure at two points brought out by Dr. MiBride, namely: (1) the risk of retention of inflammatory products due to blocking of the auditory passage by caling of a pack of boracic acid in the "dry method" of treating an otorrhcea, and the caution of vigilant attention of the aurist when this treatment was adopted; and (2) the importance of pain and facial paralysis with recurrence of granulation polypus after removal as an urgent reason why perforation of the mastoid should be performed. Mr. Black showed a skull in which it would have been quite impossible to have performed the operation in the plan often recommended, namely, a perforation of the bone half an inch behind and the same distance above the centre of the meatus without penetrating the wall of the lateral sinus. The perforator or drill was advocated, as dispensing with the jarring effect by which the use of the mallet and gouge was of necessity accompanied; but the only sure way of avoiding the lateral sinus was to hug the upper and posterior wall of the external auditory meatus.-Dr. CHARLES WARDEN, in replying, said he was of opinion that dead bone in each ear was very rare; he had never known an instance. With regard to eye closure caused by disease of the athmoid, there was no evidence of any mischief in that region, the only condition being secondary to the others. Mastoid inflammation and abscess were not always the result of otitis media. He had known cases arising from external injury. With regard to the use of dry powders, boracic acid, etc., and packing therewith, the difficulty was that one was not able to see the patients often enough, in which case the powder was left from day to day, not acting as an absorbent, but as a direct plug, which he considered most dangerous, as it simply locked a discharge of matter which should have a free exit. His preference was for boracic acid solution, zinc, and carbolic, etc.-Dr. MCBRIDE, in reply, said that in spite of what had been said he must adhere to his views as to the advantages of the chisel. The objections as to doing harm by concussion were purely theoretical. The difficulties of diagnosing intracranial lesions, both as to their commencement and as to their nature was touched upon. As to constitutional treatment, he failed to see how it could do more than palliate; it could not produce drainage. Dr. McBride could not agree with the President's suggestion as to mastoid opening in cases of perforation of the membrana placida, as in such cases the suppurating cavity was often shut off from the tympanum, and could not be reached by through irrigation.

Adenoid Growths in the Naso-Pharynx.-Mr. Lennox BRowne, in opening the discussion, said it was probable that many members attending the Section, who were specialists, might, on the announcement, have thought that the subject had been so thoroughly thrashed out that all would be inclined to cry "agreed!" and he especially referred to the excellent papers which were delivered in the Section of Laryngology at the meeting of the International Medical Congress in 1881, as ren- 
dering needless any detailed account of etiology and pathology. He thought, however, that this renewed discussion was useful, first, with a view of recording results, and secondly, to consider whether the importance of the subject had been over exaggerated, or whether it might not be extended to still larger limits. This latter was his opinion. Amongst some of the points which an extended experience had proved might be mentioned the relation of adenoid growths to enlanged tonsils. It would be found that not only were there growths where the tonsils were not enlarged, but that in almost all cases of deafness formerly considered due to enlarged tonsils there was coexistence of adenoids, and that failure to cure deafness after tonsillotomy would be less if the vault of the pharynx were always explored and cleared of additional lymphoid overgrowth. . It was also probable that adenoids did not disappear at so early an age as was generally advanced, and several cases were quoted in which they were present and were the cause of deafness in patients more than 21 years of age. A moot point was the relation of adenoids to the exanthemata-whether the former predisposed to suppurative and nonsuppurative catarrh as a sequel, or whether the growths themselves were started into activity as a direct consequence of the fever. Probably each condition might occur in different cases. Hitherto adenoids had been looked for principally in relation to non-suppurative middle-ear deafness; but experience went to show that if equal attention was directed to the pharyngeal vault many obstinate cases of otorrhoea with perforation would be more amenable to treatment. With regard to the use of anæsthetics, it was advanced that they were not needed where, as in hospital practice, the surgeon could operate so soon as the diagnosis was made, that is, on the one introduction of the finger; but young children were so terrified by the examination that in those cases in which the operation had to be performed at a subsequent date deep anæsthesia was an absolute essential to success. Lastly, because these growths became absorbed with advance of life it must not be supposed that they ought not to be treated, even in cases where the symptoms were but mild at earlier ages. It was quite possible that in many cases of progressive deafness in the adult, which might have been arrested by treatment in earlier years, there had existed adenoids, and that the hypertrophic condition of the tympanic and Eustachian mucous lining in the adult was the remnant of a malady of childhood. There must always be a certain amount of submucous thickening and deposit in the naso-pharyngeal space of the adult who had been the subject of adenoids as a child, and a limited experience warranted further trial of the process of scraping of the post-nasal space where there was thickening without actual outgrowth as an aid to resolution of an adult hypertrophic middle-ear catarrh. From every point of view the subject of adenoids merited consideration from the general practitioner, because no special skill was necessary for their detection and eradication, and the relief afforded was such as to greatly enhance the results, not only of the treatment of deafness in childhood, but of the speech, intelligence, and general well-being of all subjects of the disease.

The Rôle of the Pharyngeal Tonsil in Health and Disease.-Dr. William HrLe (London), after some historical remarks, said it was curious that no serious attempt had been made to ascertain the function of so constant a mammalian structure, for only by correct physiological considerations could the etiology of hypertrophy of the pharyngeal tonsil (adenoid growths) be satisfactorily comprehended. After drawing attention to the comparative anatomy and histology of the gland, the author contended that, as the structure was homologous, so was the function of the tonsil analogous to that of an ordinary lymphatic gland, namely, the production of leucocytes for the blood. Such leucocytemanufacturing organs, though usually situated in the course of the lymph stream, were very favourably located on the banks of the alimentary canal, for the raw materials necessary for continuous production were constantly flowing contiguous to, and were absorbed by, the adjacent mucous membrane. It was important not to confound this absorption by the mucous membrane (and the passage of some of the nasal and pharyngeal fluids into the tonsil) with the primary manufacturing rôle of the gland. Althourh the bulk of the leucocytes produced passed into the blood, histological investigation showed that a pretty constant migration took place into the alimentary canal, and it was suggested that these migratory leucocytes, being strongly amylolitic, played some subsidiary part in the processes of digestion. This same migration probably obtained in the case of the other lymphoid masses lining the alimentary tract. If these views were correct, they easily understood why pathological changes in the pharyngeal tensil were 80 constantly associated with strumous and such other colstitutional states of the system as implied contaminated and diseased nasal and buccal secretions; and it served to explain why the mere surgical treatment of adenoid growths was often so unsatisfactory.

Post-Nasal Growths.-Dr. MACFIr read a paper on this subject. for Dr. ADOLF BroNNkr, of Bradford, dealing with the following points: 1. The frequent occurence of the growths in children. Fle had recently examined 250 school children in Bradford, and found that out of these $\mathbf{2 5 0}$ children, twenty, or 8 per cent. showed the symptoms of adenoid growths in a very marked degree. 2. The intimate relation between adenoid growths and diseases of the middle ear. Of 152 cases of adenoid growths, which he had carefully examined and operated on, 125 , or 85 per cent. showed symptoms of past or present affections of the middle ear. 3. The fact that the adenoid growths were in most cases limited to the region of the vault of the naso-pharynx; in fact, that they were simply a hypertrophic condition of the pharyngeal tonsil. 4. The hest metliod of remoring the growthe was by the use of Hartmann's curette: for the following reasons: 1. It was the simplest method. 2. The operation was not very painful, and over in a few seconds. 3. Because the operation could be performed without the use of an anæsthetic. 4. There was no danger of wounding any important structure, such as the septum, the Eustachian prominences. [A series of adenoid growths which had been removed by Dr. Bronner was shown.]

Stammering or Stuttering and Naso-pharyngeal Disecase-Dr. FARQUHAR MATHESON read a paper on the relation between nasopharyngeal diseases and stammering and stuttering, which showed that this latter condition was caused in most cases in enrly life from growths and diseases of the nasal cavities. Several cases were related in which the removal of adenoid growths from the naso-pharynx completely cured the stammering and stuttering. The conclusions based on these and other cases were: $(1)$ that stammerers were, as a rule, of a neurotic temperament; (2) that one of the following conditions was a constant factor in cases of stammering-namely, enlargement of the turbinated bones, adenoid vegetation in naso-pharynx, cluronic rhinitis. The explanation given showed that the sprsmodic motion of the muscles of the throat was due to reflex irritation.-Dr. M CKENzIE JoInNston said in the first instance he should like to refer to the cause of alenoid growths. Chronic nasal catarrh, the strumous diathesis, the exanthems, were all credited with a share in the causation; but he was glad to hear Dr. Hill's reference to the digestive organs. He himself had so often found what he might call " digestive incompetence" associated with these cuses that he was inclined to look upon this as a cause. He was aware that it would be stated that the discharge swallowed from these growths was the cause of the gastric disturbance; but the gastric and lithic diathesis was, in his experience, so frequent in adenoids that he could not help thinking there must be some causal relationship. With reierence to nasal catarrh as a cause, it was curious that in America this catarrh was exceedingly common, while, as shown by Traub, of Cincinnati, and Beverley Robinson, of New York, adenoid grow ths were rare in that country. Meyer had found deafness in 60 per cent. of adenoids, so that their effect upon the ear might at ouce be admitted. He thought that they acted (1) mechanicaliy; (2) by inflammation of the surrounding tissue and extension along the Fustachian canal ; (3) extension to the middle ear, producing catarrhal and suppurative conditions; (4) by the reflex agency of the vasomotor and trophic nerves, as shown by Dr. Mckenzie, of Baltimore; and, lastly, by producing paresis of the palato-tubal muscles. There could be no doubt that, if treatment of these growths were neglected, it would be impossible to clire either cases of middle-ear catarrh or of suppurative disease. The midule ear drnined by the Eustachian canal; and therefore, if these growths prevented the proper draining of the cavity, they failed to get one of the most important conditions-dryness and cleanliness-for the treatment of diseases of the ear. The effects of these growths on the general health were sufficiently serious to require careful consideration, but these hardly came under the subject of discussion. In conclusion, he expressed a decided preference for the forceps in plice of the finger so much lauded by Mr. Lennox Browne, - Dr. How ARI said that while quite alive to the dangers in using anasthetics in operations on the naso-pharynx, he always used chloro form, and thought that with precautions against the flow of 
blood into the larynx, the danger could be reduced to a minimum. He specially emphasised the importance of drawing forward the head in introducing the finger, so as to relax the soft palate and give the maximum of space, and secondly throwing the head back and downwards over the edge of the table when the patient was under chloroform and the blood began to flow, the position of the head making it impossible for the blood to get into the larynx.Dr. Latrence Turnaul (Philadelphia) was glad to have the opinion of Dr. Howard in reference to the danger of the use of chloroform in so comparatively trifling an operation, and the discussion bringing forth the information of the death of two individuals from this cause. He was of the opinion, and had so expressed it in his Manual of Anosthetics, that in such a class of operations systemic anæsthetics were not necessary, and should not be employed when they had such an admirable local anxesthetic as the hydrochlorate of cocaine. He had found that all operations on the nose or throat could be successfully performed with a 2 or 4 per cent. solution of cocaine; the cocaine was best dissolved in a 1 per cent. watery solution of pure crystallised carbolic acid, which assisted the action of cocaine and prevented nerrous symptoms. - Dr. Charles Denison (Denver, Colorado) answered an inquiry, made by Mr. Lessox Browse, as to the frequency of these post-nasal adenoid growths in his section of country. In so far as his experien se went, he could not say that either these growths or enlargements of glands generally were so frequently met with in the clear, dry atmosphere of Colorado as in sections bordering on the ocean. The circulation of the blood was a clearer and more perfect process in the high altitudes, and glandular enlargements were not so apt to occur Yet there was a mechanical effect. so to speak, of the dry air upon the nasal mucous membrane, creating irritation through the constantly drying effect of the atmosphere, especially in the winter season.Dr. WAXHAM (Chicago) simply agreed with Dr. Turnbull that adenoid growths were comparatively rare in America. His experience had been that the obstruction in the post-nasal space which was frequently met with was due to hypertrophy of the mucous membrane and of the pharyngeal tonsil rather than to adenoid growths.-In reply to a question from Mr.GBoRG E STONE (Liverpool) the Presidenct did not believe that where the growths were very tough the finger-nail would suffice for their complete removal, and though' that Loewenberg's forceps, or some modification of it, was essential.-In answer to a question as to the latest age at which these growths had been found, Mr. Lensox Browne gave the age of 25 .- - Ir. JAsISS BLACK believed the natural finger-nail, when well-developed, was the best instrument, because it was in close contiguity to a tactile organ; but still, the fact of some men, that is, Dr. Bronner, discarding the finger-nail in favour of the curette seemed to show that in certain cases some other instrument was necessary. In most cases, however, the natural or artificial nail was necessary to complete the operation after another instrument had been used for the removal of the adenoid growths in the naso-pharynx, and the reason why was, that the choane were often blocked by thickening of the mucous membrane around these openings, and it was his (Mr. Black's) opinion that the only safe way to remove this thickening was by the use of the nail. Not possessing a well-developed finger nail, the speaker procured one of the artificial nails usually recommended, but was inconvenienced by the amount of steel of which the instrument was composed, and he had had a modification of the instrument made by Mlessrs. Wright and Co., of Bond Street, London, in which, by two relatively large fenestrae, the amount of metal was reduced to a minimum. It was enabled to fit either index finger, by the fact that the rings through which the extremity of the finger was passed, were incomplete, which gave a certain expansive advantage, so that the instrument could fit fingers of slightitly different sizes. The importance of securing the artificial nail by a string passed around the wrist was dwelt on, in order to prevent the risk of the instrument slipping, or rather being dragged off and possibly getting into the larynx.-Dr. FABQUHAR Matheson referred to the early existence of adenoid growths, resulting in many ceses from vaginal secretions at birth, as also ophthalmia, etc. This was as frequently the cause as scarlet fever. Removal with the finger-nail was preferable to the use of any instrument. An anæsthetic ought to be carefully administered, and a weak alkaline solution for nasal injection to be continued for some weeks after.-Dr. WALTER WoLsToN (Edinburgh) said that a very large percentage of the deafness now existing in Great Britain-his experience would venture to say above 75 per cent.-was due to the presence of adenoid regetation in the naso-pharynx. Were the general practitioners alive to the existence, symptoms, and facility of removal of adenoid growths, countless drumheads might be saved, and lives secured from being embittered by deafness. The operation for removal of adenoids had been called a "minor" one, and so it was from one point of view, and easy to a skilled hand, but its results were 80 brilliant that it should be thoroughly done. To effect this he thought an anæsthetic was necessary. Were the deaths under chloroform for the operation compared with those occurring in other greater operations, he doubted if any remarkable mortality would be found to exist. He thought it was of great importance to have the patient completely narcotised, carefully gagged by an assistant, and, by suitable straps, rendered incapable of struggling. He used Loewenberg's forceps to clear the larger masses, and then, with the finger-nail, completely scraped out the choane, vault, and pharynx, and various crypts and recesses of the post-nasal space, paying particular attention to the little cushion that almost always lay just above and pressed on the extremity of the Eustachian tubes. The finger-nail alone would not suffice in all cases, as in those above seven years of age the growths, often of a fibrous character, which sprang from the posterior wall of the pharynx, were so embedded in the normal tissues that a considerable amount of a cutting wrench with the forceps was necessary. This action he often supplemented by placing the forefinger of the left hand just below the mass, which prevented the pharyngeal wall being too much pulled on. It was well to reduce the posterior turbinated bodies if they were very large, and this he did by the galvano-cautery loop passed through the anterior nares. The removal of even small masses of tissue would often give remarkable results, in proof of which he related the following case: A young lady, aged 27 , contracted a severe catarrh, accompanied by intractable oneezing, which lasted ten days, but was subdued immediately by a 4 per cent. spray of cocaine. Deafness for two months was complained of, and did not give way to the air-bag. Examination showed the pharyngeal tonsil to be very turgid and impinging on the tubes. Under chloroform he removed tissue only the size of a horse-bean. Within a week she heard as well as ever, and at the end of three months quite twice as well as before, and, in addition, found that she had gained three semitones in her singing roice, now reaching A-flat, whereas $\mathrm{F}^{\prime}$ had been previously her highest note.Dr. BARR (the President) thought the men who brought this subject before the profession, such as Meyer, Guye, and Loewenberg, had performed a most important service to aural surgery; indeed, the discovery of these growths as sources of ear disease marked an important epoch in the development of the knowledge of ear disease. There was no doubt that these growths were very frequently met with in Scotland, and were most important causes of ear disease. In their operative treatment Dr. Barr employed finger nail artificial steel nail, and Loewenberg's forceps, or modifications of them. He preferred, as a rule, the steel nail and the forceps to the finger-nail. The latter was not sufficient to remove the tough growths, and was not so cleanly a method as instruments. Dr. Barr frequently employed first the forceps and then finished with the artificial nail. The introduction of proper forceps into the naso-pharynx was less painful than the finger, but the sensitiveness varied very much in different persons. Local application of cocaine was very useful, but it was well to avoid chloroform, although in very nervous children this anfesthetic was necessary. If chloroform was employed, the head should be placed well down so as to avert the possibility of blood entering the windpipe. One operation was not usually sufficient to completely clear out the regetations, and three or four might be necessary before a smooth condition of the mucous membrane and a permeable state of the nasal channels were secured.-Mr. LEN wOX Bnow NE, in reply, referring first to the question of anæsthesia, repented that if operation were done at the time of first examination, no anæsthetic was required. Although the effect of introducing the finger into the naso-pharyngeal vault was disagreeable, and, in young children, somewhat terrifying, it was by no means really painful, and local aniesthesia by means of a cocaine spray of 10 per cent. strength was quite sufficient to annul all sensation. Although he preferred the finger-nail for removal of these growths, and had never found a case in which it could not be employed with success, he desired to accord the greatest liberty of action to everyone on this point. The important thing was not what instrument was used, but how to attain a good result; and, personally, be very rarely found it necessary to repeat an operation by his method, while three or four repetitions of procedure by forceps had been admitted by 
various speakers. Many members not having heard his introduction had unconsciously repeated his own observations, and he was glad to have such independent confirmation of his views, as, for instance, with regard to the presence of adenoids in persons of advanced age, and of their influence on the singing voice. Doubtless in some portions of America adenoid growths were rarely found; but one of the best monographs of recent date was that of Dr. Hooper, of Boston, who had recorded a large experience. Mr. Browne spoke of the possibility of sending blood into the middle ear, and thus causing suppuration in that situation, if Politzer inflation, or even syringing of alkaline solutions, were pursued immediately after the operation, and he recommended observance of Meyer's advice to leave the parts completely at rest for a few days. Ife also spoke of protection of the finger from biting by means of a leather guard, as suggested by his colleague, Dr. Dundas Grant. This was preferrable to the metal lobsterclaw guard, which last did not protect the portion of the finger usually attacked. Reference was also made to etiology. Without doubt digestive derangement was an effect rather than a cause.

Artificial Tympanic Membranes.-Dr. MACFIE read for Dr. LAIDLA W PURves a paper on this subject, which is published at p. 478.-Dr. Turneule (Philadelphia) read a paper, in which the following conclusions were expressed :-1. That such aids were important to the health of the ear, by preventing dryness and the general danger to the hearing, from the want of the protecting power of the natural membrane. 2. A certain degree of hearing would be possible without the membrana tympani, but perfect hearing was impossible without it. 3 . In the various agencies which had been employed they had not only the means of protecting and preventing drying effects of the air, but also the prevention of the passage into the middle ear of injurious foreign agents, the prevention of disease from cold air or water, so apt to set up acute inflammation, followed by abscess in the mastoid or brain. Satisfactory results had been obtained from the cotton ball or pellets of "Yearsley." The objection to this was the tendency which the ordinary cotton had to cause irritation, by bearing in its fibres bacteria and micrococci; also other foreign matters. Again, it sometimes fitted so closely, owing to discharge or mucus on its surface, as to make a shut sac, and absolutely prevent the vibrations of the membrane, thus acting as a damper These difficulties were overcome by employing corrosive sublimate solutions with " sublimate cotton," or a disc of sublimate gauze, moistened with fluid cosmoline, so as to make it more adhesive. When water with glycerine was employed the mixture would soon ferment in the ear and become irritating and cause inflammation. By treatment they could much sooner employ the artificial membrane, even when there was a slight suppuration going on. The solution of the sublimate should not exceed in strength 1 to 4,000 ; if stronger it gave pain. The patient was supplied with a dozen or two of these cotton pellets, attached to threads which had also been soaked in the solution. The fluid cosmoline, or vaseline, was to moisten the pellet when about to be introduced, if the parts were dry. The pellets were placed in position by means of ordinary tweezers; the thread must be cut off close, so as not to be seen. The second form was the india-rubber disc, cut out with the apparatus of Gruber, and introduced with the forceps, as seen illustrated in the writer s work (Clinical Manual of Diseases of the Ear, 2nd ed., 1887, p. 489. J. B. Lippincott and Co., Philadelphia). He (Dr.'Turnbull) had discarded all the forms of apparatus which had any metallic spring, handle, etc., having found them always irritating and injurious. He applied a disc of "Mead's adhesive plaster," which was found to be perfectly pliable and antiseptic, or the same make of "boric acid plaster." He had had reports from almost every case of its success in relieving deafness, assisting the perforation in closing, the plaster being retained for months, and in one case two years, with but little irritation. Dr. C. M. Thomas, of Philadelphia, informed him (the speaker) that he had found the "oil silk," such as was employed in antiseptic dressing, a very successful artificial membrane, looking and acting like the natural one. He cut them the size required. leaving a small opening in the centre. Dr. C. S. Turnbull, the speaker's son, employed with success a pledget of antiseptic wool, placed near to but external to the annulus tympanicus.

Fraudulent Treatment of the Deaf by Impostors.-Mr. RICHARD ELLIs (Newcastle) read a paper on this subject, in which he said that patients affected with chronic deafness were always ready to listen to anyone who would give them hope. This was often taken advantage of by impostors. Seeing at the institution to which he was attached a very large number of deaf cases, he was, some months ago, surprised by the number asking with great regularity, when he told them the nature of their cases, the same question, namely, "Would an artificial drum do any good?" Following this up, he found it was in consequence of the insertion in the newspapers of an advertisement from a person in London, offering to cure deafness by the use of patent artificial drums with gold cylinders ; and, further, he found the cure was stated to be applicable to all forms of deafness, "of however long standing." $\mathrm{He}$ had there for inspection a small box of those precious artificial drums, brought to him by a working man, and for which he paid $£ 217 \mathrm{~s}$. 6d., which he stated he could very badly afford at the time, but which he was induced to send by the positive promises of cure held forth. He (Mr. Ellis) had had the metallic portion of these drums examined by a goldsmith, and he pronounced them "brass"-which he thought they would agree with him was a most appropriate metal. The poor man who was induced to purchase these drums suffered from nervous deafness and tinnitus, and had nothing whatever the matter with his tympanum or conducting apparatus, and Mr. Ellis purposely avoided entering into the question of the applicability of the artificial tympanum, but from the various impositions practised under its cover, he was sometimes inclined to ask, Was the artificial tympanum a blessing or a curse? Might they not, failing to cure some of their patients, at least endeavour to save them from imposition and fraud by exposing the nefarious schemers who lay in wait for them?-Dr. MATHESON mentioned that artificial membranes in deafness were of considerable assistance in two conditions of the membranæ tympani. The first condition in which they aided hearing, was that of collapse and irregularity of the external meatus and in retraction of the membrane from chronic catarrh. The second condition in which artificial membranes were of use was in the absence or perforation of the membranæ tympani. The most useful form of artificial membrane was the cotton-wool plug (antiseptic) and a covering or plug of boric acid. All discs of tissue of whatever variety acted as irritants, and should be used with much caution. The application of boric acid favoured healing and cicatrisation of the perforation, as well as improving hearing.-Dr. DoNALD STEWART said that with reference to artificial membranæ tympani, the difficulty of deciding whether the artificial membrane was a means to avoid dampness of the membrane or a means to introduce the necessary moistness was an important point. In health the membrane was quite dry, and in this uncertainty they had a pregnant hint to take care not to overtreat these cases. The danger and cruelty to the public who suffered from deafness by quacks should be condemned in the strongest terms.Dr. WARDEN said the benefit arising from the use of artificial membranæ tympani varied very much, and the best of the advantages derived was one of personal experience. The physiological explanation was that the bones of the meatus, especially the stops, were supported by the pressure, and the nervous apparatus of the internal ear affected. The plan he adopted was gradually to arrest the discharge in cases of the otorrhoea with perforationthe only cases in which he used it, and the only one in which any benefit accrued; and his preference was for Field's drums or a modification of Toynbee's or Yearsley's.-Mr. RICHARD ELLIS had not found the artificial tympanum of much use in hospital practice, but in a number of cases in private practice it was undoubtedly serviceable. He had found the invention of Dr. B. W. Richardson, which consisted of a hollow cylinder of gold, useful. He had found boracic acid useful in perforation of the membrane, but it required care in its use, and should be watched and changed.-Dr. WALKER DownIE agreed with Dr. Warden when he said that the results from the use of artificial tympanic membranes were very variable, and could never be predicted. As a preliminary, Dr. Downie was in the habit, after all suppuration had ceased, of using a layer of cotton-wool firmly compressed between finger and thumb, and applied by a pair of fine forceps; these could afterwards be readily applied by the patient himself. Should this not succeed, he frequently used Field's pattern. Lately he had, partly as an experiment, been applying a small circular patch of pellicle of egg, which was soft and lay firmly in contact with the membrane. This he dipped in a saturated solution of boric acid before application, and, should the desired condition be entirely remedied, that is, no suppuration present, they could be left in situ for several weeks. Dr. James ERskine had found Professor Lucae's artificial tympanic membrane very useful. It had the advantage of being very 
easily inserted, and no injury could happen to the meatus in its introduction. He had come to the conclusion that the cottonwool pellet of Yearsley's invention was the best artificial drum membrane. Dr. Turnbull's paper contained a complete catalogue of everything that had been utilised for this purpose, but the experience of most surgeons was that the simple cotton was generally found the best. If it failed, the india-rubber disc of Lucae and other appliances might be tried. He did not approve of the use of boracic acid powder as an artificial membrane in the way Dr. Farquhar Matheson had described, as there was a great tendency for the powder to cake and dam up the pus that might be forming in the tympanum. With respect to the quacks referred to by Mr. Ellis, he would like to make a remark. The late Mr. Syme, of Edinburgh, was credited with saying that curable ear cases were treated by general practitioners, and the incurable cases by specialists. Nowadays it was true that curable cases were treated by specialists and incurable cases by quacks.-Dr. BARR (the President) said the cotton pellet was on the whole the best form of artificial tympanic membrane. The india-rubber disc was however occasionally, though rarely, more efficient. As usually sold by the instrument maker it was very defective, as from the mode of connection of the disc with the stem a hard metal knob pressed upon the tympanic structures. He (Dr. Barr) regarded the cotton pellet properly applied in suitable cases as a most valuable aid to hearing, and in cases of complete destruction of the tympanic membrane, or of the postero-superior part, when the nerve structures were fairly normal, probably 75 per cent. were benefited. Before employing this aid to hearing, the purulent secreting process, if present, should be cured, or should be reduced to a very small compass, and great care should be taken at first that it should remain in the ear only for a short time, not more than two or three hours, otherwise a fresh purulent process might be excited which would greatly discourage the patient. It should rarely be allowed to remain in the ear during the sleeping hours. Before deciding as to the value of this remedy in any given case, we must take great pains to try more than once various sizes and shapes in various positions. He believed that many failures were accounted for by the want of sufficiently painstaking efforts in those directions. A certain degree of pressure was usually necessary before the good effect was achieved, and while the postero-superior quadrant was usually the best position, trial should be made over the short process of the malleus, and indeed on any part in the upper regions of the tympanum. The pellet should be moistened, preferably by some thickish antiseptic fluid. In some cases where the cotton pellet or disc was apt to become misplaced, falling out from its proper position, it was a good thing to immerse the cotton in collodion and apply it to the part. In this case, if the ear could bear prolonged contact, it need not be removed for days or weeks. $\mathrm{He}$ knew a patient who kept it in the ear day and night for months when the collodion was applied. The patient should be most carefully taught the mode of using the pellet of cotton with all due precautions before finally dismissing him, and until the patient had become dexterous in the mode of withdrawing the pellet, the precaution should be taken of fixing a piece of thread to the pellet in order that it might be easily withdrawn. Dr. Barr expressed the opinion that the so-called "ear-drums," so extensively advertised in the newspapers, and which consisted of a piece of india-rubber attached to a metallic stem, were frequently highly injurious to persons with defective hearing, that the number of deaf persons who might be benefited by this form was comparatively small, and that in no case should an artificial drum of any form be used until a surgeon had examined the defective ear and ascertained if the case was suitable, for if not suitable their introduction into the ear was not merely valueless but decidedly injurious.-Dr. TURNBULL, in reply, referring to the abuse of the artificial membrane, said this depended upon the want of care in the selection of cases and the kind of cotton used. It should in all cases be sterilised cotton in one long fibre, to remove pus which might be formed, or a pledget of cotton of a round form, moistened with cosmoline. Dr. Turnbull objected to pure glycerine on account of its absorbing water, and, if there was no water, it would dry the cavity. It should be mixed with pure water, and could be given to the patient with safety. He had no special plan in all cases, but, by testing the hearing with the tuning-fork and watch, found out by such means what would be best for the patient.-Dr. J. MACFIF said that, although the discussion had been successful in many ways, he somewhat regretted that it had taken an almost exclusively practical turn, with the exception of the President, only one or two members having alluded to what was an important part of Dr. Purves's paper, that is, the influence produced by the artificial drumhead on the sonorous vibrations, and how this was brought about. At that advanced hour he (Dr. Macfie) did not think of taking up that part of the subject ; with regard to the rest, he said we need not expect to find one form of artificial drumhead applicable to all cases amenable to improvement by this treatment, the form varying with the case, but he thought the most generally applicable was Yearsley's cotton plug, or some modification of it. He agreed with Dr. Farquhar Matheson as to the dangers of boracic powder, especially when packed into the ear, unless the patient was almost daily under the observation of the surgeon.

\section{CLINICAL MEMORANDA.}

\section{ECTOPIA CORDIS.}

IN the JoURNAL of July 21st, the Liverpool correspondent mentions a case of transposition of the heart and liver. As such cases are somewhat rare, I may be permitted to record one that came under my notice a year or two ago. The subject was a fairly strong, middle-aged man, who had consulted me for some trifling ailment when I first noticed something abnormal. On placing the stethoscope over the cardiac region, there was a complete absence of heart-sounds, while on percussion the resonance was as marked as over any other part of the chest. Further examination revealed the presence of the heart on the right side, in a position as nearly as possible corresponding to its normal one on the left, the apexbeat being easily made out between the fifth and sixth ribs on the right side. The man met with his death accidentally soon after, and this prevented me from making a further examination as to the position of the liver, etc., nor was I allowed to make a postmortem examination of the body.

Coniston.

JoHn KendaLL, L.R.C.P., etc.

\section{OBSTETRIC MEMORANDA.}

\section{ABSENCE OF:RIGHT PARIETAL BONE.}

ON June 28th, 1888, I attended Mrs. B. in her confinement. On examining the child-a fine healthy boy born at full term-I found that the right parietal bone was absent. Over its site the skin was loose and distended with fluid; palpation produced fluctuation. By pressing the fingers firmly into the margin of this swelling I could distinctly define the edges of the surrounding bones. This was verified daily during the subsequent nine days' attendance.

A month later I again saw the child, and found that the site was now occupied by bone, with the exception of a small circular space rather less in size than a shilling, situated about midway between the parietal eminence and the posterior superior angle of the bone.

On August 22nd I visited the child, and was told that the "hole had filled up" a week after my last inspection. The bone was quite firm, but somewhat nodular, especially over the site of the space that was last to disappear. The case must, I think, be one of extreme rarity, first, on account of the deformity being symmetrical, and secondly, because of the way in which the bone was developed (?). The labour was an easy and rapid one, and the swelling, which somewhat resembled a caput succedaneum, instead of diminishing during the next day or two, distinctly increased daily for three or four days.

Mornington Crescent, N.W.

$$
\text { G. WASHINGTON IsAaC, M.B., C.M.Edin. }
$$

\section{CASE OF ABORTION OF FCETUS AND MOLE, WITH ANTEFLEXION OF UTERUS.}

I was called to attend Mrs. H., aged 30, multipara, suffering from eevere pain in the lower part of the abdomen and difficulty of micturition. She informed me that she was four months pregnant, and that the membranes had ruptured on the previous day. On examination I found a large rounded mass anteriorly extending low down into the vagina, which proved to be an anteflexed uterus. I reduced the anteflexion and ordered her to remain in bed. About fourteen hours afterwards a putrid fotus was ex- 